\title{
Virus respiratorio sincicial. Patrón clínico epidemiológico en niños internados en un hospital pediátrico durante los años 2000-2013
} Respiratory syncytial virus. Clinical and epidemiological pattern in pediatric patients admitted to a children's hospital between 2000 and 2013

\author{
Dra. María Florencia Lucion", Dra. María del Valle Juarez ${ }^{a}$,Dra. Mariana Viegas ${ }^{b}$ \\ Dra. Vanesa Castellano ${ }^{a}$, Dra. Viviana Sandra Romanin ${ }^{a}$, Dra. Marcela Grobaporto ${ }^{a}$, \\ Dra. Julia Bakira , Dra. Alicia Susana Mistchenko y y Dra. Ángela Gentile ${ }^{a}$
}

\section{RESUMEN}

Introducción. El virus respiratorio sincicial (VRS) es el principal agente asociado a infección respiratoria aguda baja en niños. El objetivo de este estudio fue describir el patrón clínicoepidemiológicoe identificar los factores de riesgo de infección por VRS.

Población y métodos. Estudio prospectivo de cohorte de pacientes internados por infección respiratoria aguda baja en el Hospital de Niños Ricardo Gutiérrez, marzo-noviembre, 20002013. El diagnóstico viral para VRS, adenovirus, influenza y parainfluenza se realizó por inmunofluorescencia indirecta de aspirados nasofaríngeos.

Resultados. Se incluyeron 12555 niños; 38,2\% (4798) presentaron rescate viral; el VRS representó el $81,8 \%(3924 / 4798)$ sin variaciones anuales significativas $(71,2-88,1)$, con patrón epidémico estacional(mayo-julio); fueseguido por influenza $(7,6 \%)$, parainfluenza $(5,9 \%)$ y adenovirus $(4,7 \%)$. Los casos con rescate de VRS (3924) tuvieron una mediana de edad de 7 meses (0-214 meses); $74,2 \%$ eran menores de 1 año; $43,1 \%$, menores de 6 meses; 56,5\%, varones; y la manifestación clínica más frecuente fuebronquiolitis $(60,7 \%)$. El $41,6 \%$ tenía comorbilidades; las más frecuentes, enfermedad respiratoria crónica $(74 \%)$, cardiopatías congénitas (14\%) y enfermedad neurológica crónica $(10,2 \%)$. El 25\% presentó complicaciones. La letalidad fue 1,9\% (74/3888). Los predictores independientes de infección por VRS fueron la edad $<3$ meses [OR 2,8 $(2,14-3,67)$, $\mathrm{p}<0,01]$, la bronquiolitis como presentación clínica [OR1,54 (1,32-1,79), p < 0,01] y la presencia de hipoxemia al momento del ingreso [OR 1,84 $(1,42-2,37), \mathrm{p}<0,01]$.

Conclusiones. La infección por VRS presentó un patrón epidémico estacional y se asoció más a niños pequeños menores de tres meses con bronquiolitis e hipoxemia al momento del ingreso.

Palabras clave: virus respiratorio sincicial, bronquiolitis, epidemiología.

http:/ /dx.doi.org/10.5546/aap.2014.397

Conflicto de intereses: Ninguno que declarar.

Recibido: 17-1-2014 Aceptado: 28-5-2014

\section{INTRODUCCIÓN}

Las infecciones respiratorias agudas bajas (IRAB) en los niños son una de las causas más frecuentes de consulta médica, ausentismo escolar, hospitalización y mortalidad infantil. ${ }^{1,2}$ En los países en vías de desarrollo, la mortalidad es mayor que en los desarrollados, en especial en los niños menores de 5 años. ${ }^{3}$

En Argentina, según el último informe del Ministerio de Salud (diciembre, 2012), la enfermedad respiratoria fue la tercera causa de mortalidad en niños menores de 5 años (luego de las afecciones perinatales y las anomalías congénitas), que constituye el 6,3\% (572/9037) de las muertes totales de causa definida de niños menores de 5 años en 2012. ${ }^{4}$

Los virus son los agentes patógenos más frecuentemente implicados en las IRAB, tal como lo demuestran diversas publicaciones internacionales y nacionales. ${ }^{1-5}$

El método de diagnóstico rápido recomendado para la detección de los virus respiratorios es la inmunofluorescencia indirecta (IFI). Esta técnica es ampliamente usada debido a su rapidez, bajo costo, sencillez, buena especificidad y sensibilidad. Permite identificar los agentes virales que usualmente están relacionados con IRAB, como son virus respiratorio sincicial (VRS), influenza, parainfluenza y adenovirus. $^{6-10}$

La identificación rápida de los agentes etiológicos virales resulta indispensable para el monitoreo epidemiológico de esta patología, 
brinda la posibilidad de disminuir el uso innecesario de antibióticos y, por ende, la disminución de la resistencia bacteriana, lo que mejora la atención de los pacientes hospitalizados y optimiza los recursos disponibles. Posibilita, además, la adopción de medidas tendientes a disminuir el contagio intrainstitucional mediante el uso de medidas de aislamiento de contacto o respiratorio según corresponda.

A pesar de que en los últimos años se ha realizado una enorme cantidad de estudios en los que se utilizan las técnicas moleculares para el diagnóstico de virus respiratorios, para el caso del VRS, motivo del presente trabajo, la IFI sigue siendo la técnica de elección para el diagnóstico por su alta sensibilidad y especificidad, no así para otros virus respiratorios (adenovirus). Las técnicas moleculares han logrado aumentar la sensibilidad de la detección entre el 4 y el $7 \% .{ }^{10} \mathrm{La}$ IFI es, incluso en la "era de la PCR", un método particularmente adaptado para la vigilancia continua de la epidemiología local de los virus respiratorios en la población pediátrica. ${ }^{9}$

Particularmente el VRS es el principal patógeno causante de bronquiolitis y neumonía en el lactante pequeño y diferentes estudios epidemiológicos demuestran que la infección primaria por VRS ocurre entre las 6 semanas y los 2 años de vida. ${ }^{2,11-17}$

Dada la magnitud del problema de las IRAB, es importante describir su patrón clínicoepidemiológico y la carga de enfermedad debida a VRS en nuestro medio e identificar los factores de riesgo de la infección por este virus. Esta información permitiría, en el futuro, contar con datos para trabajar en la prevención de la infección por VRS con vacunas específicas y optimizar edades y esquemas de administración y posteriormente evaluar su efectividad y ajustar así las políticas de salud. ${ }^{18}$

El objetivo de este estudio fue describir el patrón clínico-epidemiológico e identificar los factores de riesgo de infección por VRS.

\section{POBLACIÓN Y MÉTODOS}

Se realizó un estudio epidemiológico analítico de cohorte prospectivo. Se incluyeron todos los pacientes internados por IRAB, detectados a través del Programa de Vigilancia Epidemiológica (PVE) de las IRAB del Hospital de Niños Ricardo Gutiérrez en el período marzo-noviembre de 2000-2013 inclusive (14 años). Se excluyeron los pacientes con IRAB con rescate de VRS adquirido de manera intrahospitalaria.

Mediante el Programa de Vigilancia
Epidemiológica, se realiza una vigilancia activa de pacientes internados con IRAB (primer o segundo episodio broncoobstructivo en menores de 2 años y neumonías de cualquier edad). En nuestro estudio, se incluyeron los pacientes internados por IRAB con rescate de VRS. Se recolectaron los datos en una ficha epidemiológica, en la que constaban la fecha de ingreso, los datos demográficos, edad, sexo, procedencia, forma de presentación clínica (bronquiolitis, neumonía), internaciones anteriores relacionadas con patología respiratoria, reinternación del mismo episodio, comorbilidades, presencia de convivientes o contacto cercano con alguna enfermedad respiratoria aguda de probable causa viral (rinorrea, tos y/o fiebre), antecedentes perinatológicos, complicaciones durante la internación y evolución (alta, traslado a otro centros, defunción), tratamiento y tiempo de hospitalización. Como comorbilidades, se consideraron enfermedad respiratoria crónica o recidivante, desnutrición, cardiopatía congénita, enfermedades genéticas, neurológicas e inmunosupresión. Como enfermedad respiratoria crónica o recidivante, se registró la presencia de alguna de las siguientes patologías: bronquitis obstructiva recidivante (BOR) o asma, reflujo gastroesofágico, fibrosis quística del páncreas, displasia broncopulmonar, neumonías recurrentes y laringitis recurrente. Se definió BOR a la ocurrencia de dos o más episodios broncoobstructivos. Como complicaciones, se consignaron otitis, neumotórax, atelectasia persistente, sepsis, claudicación respiratoria e infección intrahospitalaria. Se consideró infección intrahospitalaria a la reagudización del cuadro respiratorio, expresado por fiebre, aumento del requerimiento de oxígeno o cambios del patrón radiológico, que se presentó en los pacientes incluidos a partir de las 48 horas de su internación y que no hubiera estado presente ni siquiera en período de incubación al momento del ingreso.

\section{Métodos diagnósticos}

El diagnóstico clínico o radiológico de bronquiolitis y neumonía se realizó de acuerdo con los lineamientos de la Sociedad Argentina de Pediatría. ${ }^{1}$ El diagnóstico virológico se realizó por inmunofluorescencia indirecta (IFI) de aspirados nasofaríngeos tomados durante las primeras 24 horas de internación. Las muestras se obtuvieron con sonda nasogástrica K-30 introducida a través de las narinas y fueron remitidas en forma inmediata al Laboratorio de Virología del Hospital.

Para la detección de los antígenos en las 
células de aspirados, se utilizó el método diagnóstico rápido por IFI. Las muestras fueron lavadas en solución salina buffer y las células separadas por centrifugación fueron depositadas sobre portaobjetos y fijadas con acetona. Se buscaron los siguientes virus respiratorios: VRS, adenovirus, influenza A y B y parainfluenza 1, 2 y 3 con anticuerpos monoclonales (Chemicon USA). La inmunofluorescencia se reveló con los sueros antiespecie correspondientes.

Para la genotipificación, se procedió a secuenciar el ectodominio del gen de la glicoproteína G del VRS, una de las principales glicoproteínas de superficie frente a la que se generan los anticuerpos neutralizantes. Los ácidos nucleicos se extrajeron directamente a partir de las muestras clínicas de ANF con el kit NucleoSpin ${ }^{\circledast}$ RNA/Protein (Machery-Nagel), siguiendo las instrucciones del fabricante. Posteriormente, el ARN se retro-transcribió y se amplificó mediante el uso del kit Qiagen-OneStep $R T-P C R$ (Qiagen) siguiendo las instrucciones del fabricante y utilizando los cebadores específicos para la región mencionada. Luego, los productos de PCR purificados se secuenciaron en ambas direcciones usando el kit BigDye Terminator v3.1 (Applied Biosystems) en el analizador genético ABI3500 (Applied Biosystems).

\section{Análisis de datos}

El análisis estadístico se realizó con el programa Epi Info versión 7 (CDC, Atlanta). Las variables cualitativas se analizaron con el test $\chi^{2}$ con la corrección de Yates. La medida de asociación utilizada fue el riesgo relativo (RR) con un intervalo de confianza (IC) de 95\%. Se efectuó un análisis multivariado a fin de establecer los predictores independientes, usando para variables cualitativas el modelo de regresión logística del programa SPSS versión 15.0. Se consideró significativa una probabilidad menor de 0,05 .

\section{RESULTADOS}

Se incluyeron 12555 niños, de los cuales el 38,2\% (4798) presentó algún rescate viral y constituye la población por analizar en el estudio.

El VRS representó el 81,8\% (3924/4798) de las muestras positivas; el resto de los virus identificados se presentaron con una incidencia muy inferior: el virus influenza representó el 7,6\% (365/4798); parainfluenza, el 5,9\% (282/4798); y adenovirus, el 4,7\% (227/4798). La distribución anual de los casos de IRAB por VRS fue 2000: 84,8\%; 2001: 71,2\%; 2002: 79,8\%; 2003: 74,7\%; 2004: 87,4\%; 2005: 84,4\%; 2006: 88,1\%; 2007: 78,0\%; 2008: 81,2\%; 2009: 77,6\%; 2010: 87,3\%; 2011: 82,8\%; 2012: 84,7\%; 2013: 71,5\% (pico mayo-julio) (Figura 1). Durante el año 2009, en la pandemia por virus influenza H1N1, el VRS fue desplazado por este virus durante el período de mayor circulación pandémica.

La mayor incidencia de casos de IRAB por VRS se presentó predominantemente entre las semanas epidemiológicas 25-30 (junio-julio), a excepción de los años 2010 y 2012, que presentaron picos más

FIGURA 1. Distribución anual de los virus respiratorios en niños internados por infección respiratoria aguda baja en el Hospital de Niños "R. Gutiérrez", 2000-2013

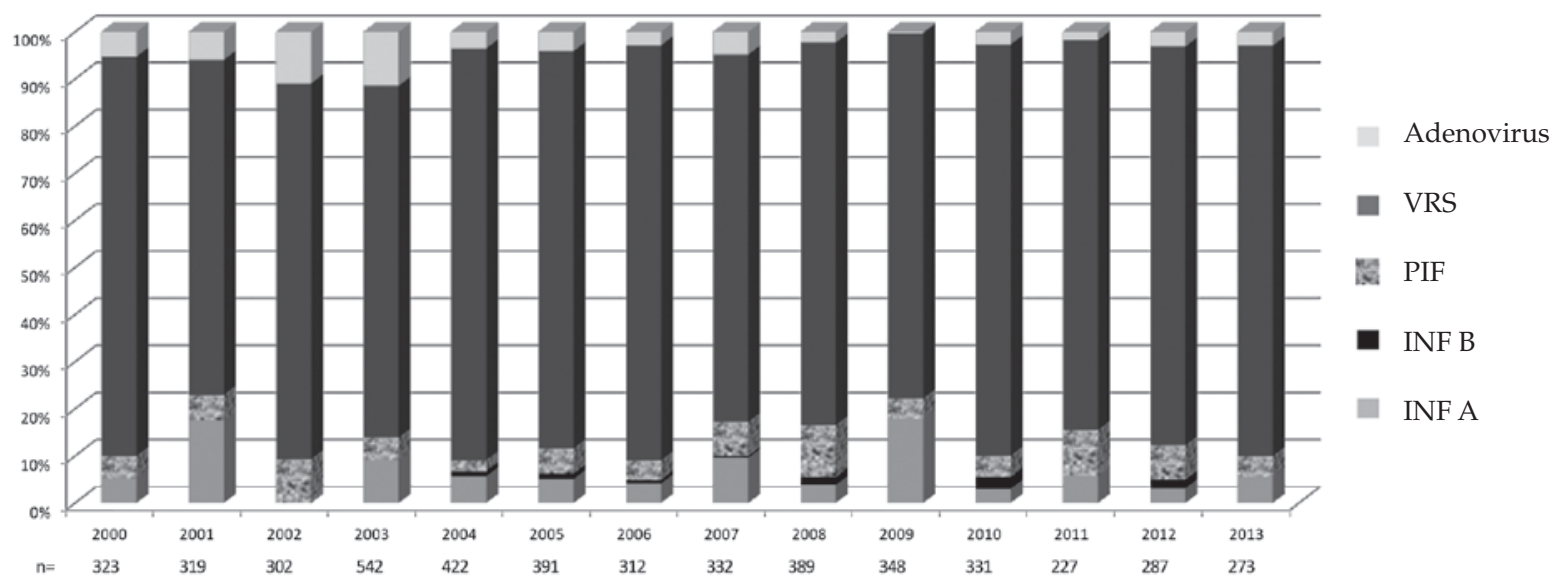

VRS: virus respiratorio sincicial. PIF: parainfluenza. INF B: influenza B. INF A: influenza A. 
precoces a partir de la SE 18 (mayo) (Figura 2).

La tasa de incidencia hospitalaria anual de bronquiolitis fue $39,1 / 1000$ (pico en 2003: $47,8 / 1000)$ y la de bronquiolitis por VRS fue de 15,4/1000 $(8-19,4)$ con un patrón epidémico estacional (mayo-julio).

Los pacientes internados con diagnóstico de IRAB por VRS presentaron una mediana de edad de 7 meses (0-216 meses). El 10\% fueron menores de 2 meses; $43,1 \%$, menores de 6 meses; y el $74,2 \%$, menores de 1 año; $56,5 \%$ fueron varones y la manifestación clínica más frecuente fue bronquiolitis, el 60,7\% de los casos; el restante $39,3 \%$ se presentó como neumonía. El $48 \%$ de los pacientes presentaban el antecedente de contacto intrafamiliar o cercano con personas agudamente enfermas.

El 3,2\% de los casos fueron reinternación del mismo episodio y el $26,9 \%$ tuvieron internaciones previas de causa respiratoria. El 41,6\% de estos pacientes tenía patologías concomitantes; las más frecuentes fueron la enfermedad respiratoria crónica (ERC) $(74 \%)$, cardiopatías congénitas $(14 \%)$, prematurez $(13,6 \%)$, enfermedad neurológica crónica $(10,2 \%)$, desnutrición $(5,1 \%)$ e inmunosupresión (1,9\%). La bronquitis obstructiva recidivante correspondió al $94 \%$ de las ERC registradas (Tabla 1).

La mediana de tiempo de internación fue de 7 días (1-200 días). El 25\% de los casos presentó complicaciones durante la internación (Tabla 2). E1 6,9\% requirió cuidados intensivos con asistencia respiratoria mecánica por claudicación respiratoria. El 6,6\% de los pacientes presentaron infecciones intrahospitalarias. La letalidad fue $1,9 \%(74 / 3888)$.

Los factores de riesgo asociados a la infección por VRS en comparación con los otros virus fueron la edad menor de 3 meses, bronquiolitis como presentación clínica y la presencia de hipoxemia al ingreso (Tabla 3).

El análisis de las características genotípicas de las cepas de VRS que afectaron a los pacientes internados durante el período de estudio (20002012) mostró que los dos subtipos de VRS, tanto

TABLA 1. Enfermedad respiratoria crónica, distribución según patología

\begin{tabular}{lcc} 
Enfermedad respiratoria crónica $(\mathbf{n}=\mathbf{1 2 0 4})$ & \\
& $\mathbf{n}$ & $\%$ \\
\hline Bronquitis obstructiva & 1115 & 94 \\
recidivante - Asma & 31 & 2,6 \\
Neumonía recidivante & 18 & 1,5 \\
Reflujo gastroesofágico & 13 & 1,2 \\
Displasia broncopulmonar & 5 & 0,4 \\
Fibrosis quística del páncreas & 4 & 0,3 \\
Laringitis recurrente & &
\end{tabular}

FIGURA 2. Serie temporal de casos de virus respiratorio sincicial en niños internados por infección respiratoria aguda baja en el Hospital de Niños "R. Gutiérrez", 2000-2013

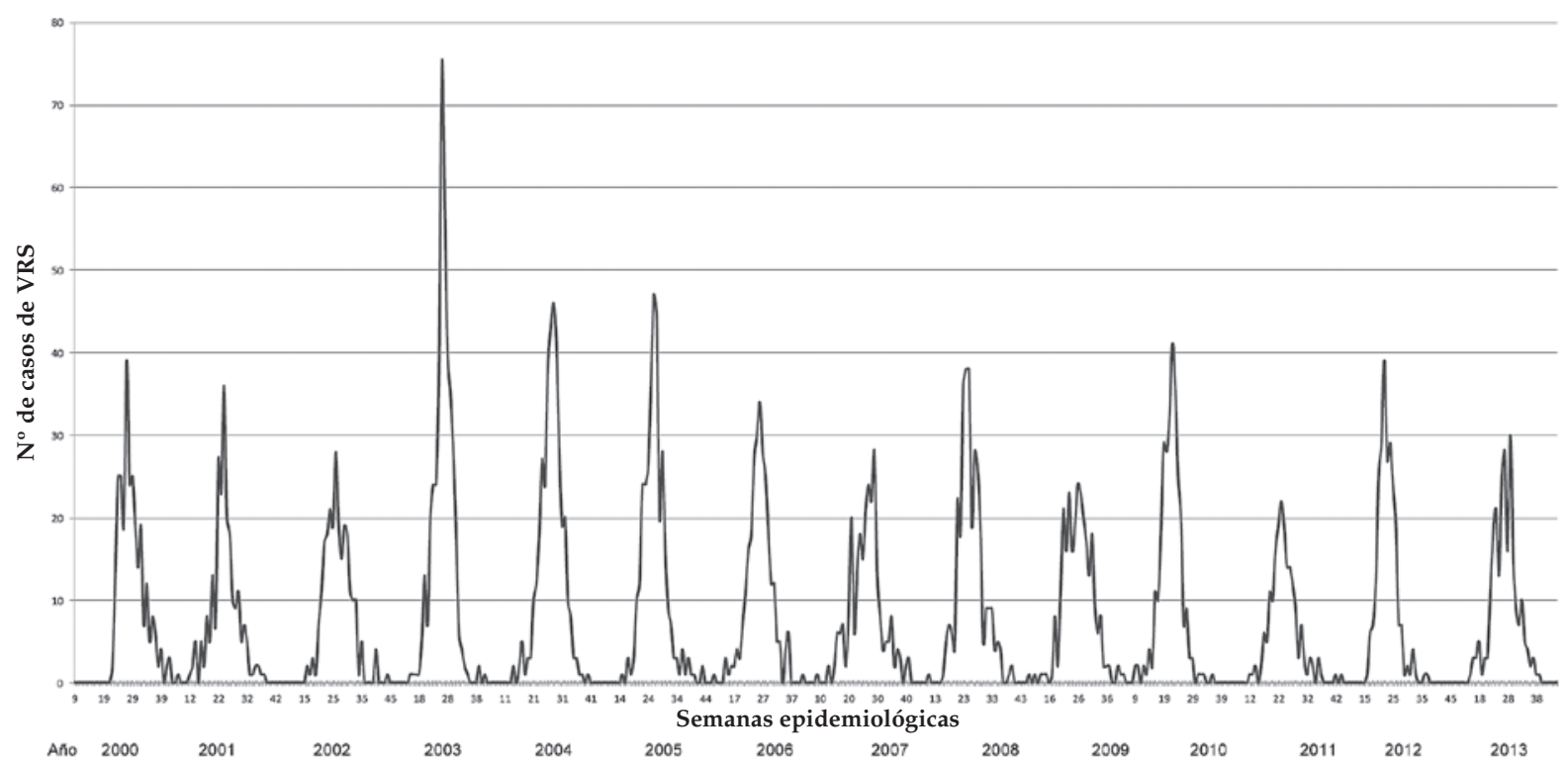


el A como el B, han co-circulado en la población pediátrica. El subtipo A estuvo presente durante todo el período de análisis excepto en el año 2005 , en el que solo se encontraron virus del subtipo B entre las muestras analizadas; sin embargo, el subtipo A fue el único encontrado en el año 2000. Las características genotípicas del subtipo B mostraron que el genotipo BA con una duplicación de 20 aminoácidos en la glicoproteína $\mathrm{G}$ respecto de la cepa patrón de VRS B/CH18537/63, descrito por primera vez en

TABLA 2. Complicaciones durante la internación, distribución según patología

\begin{tabular}{lcc}
\multicolumn{1}{c}{ Complicaciones durante la internación } & $(\mathbf{n}=\mathbf{1 2 0 8})$ & \\
& $\mathbf{n}$ & $\mathbf{\%}$ \\
\hline Otitis media aguda & 300 & 24,8 \\
Claudicación respiratoria & 302 & 25,0 \\
Infección intrahospitalaria & 243 & 20,1 \\
Atelectasia persistente & 174 & 14,4 \\
Sepsis & 133 & 11,0 \\
Neumotórax & 44 & 3,6 \\
Derrame & 12 & 1,0 \\
Total de complicaciones & 1208 & 100,0 \\
\hline
\end{tabular}

TABla 3. Análisis de los factores de riesgo asociados a infección por virus respiratorio sincicial

\begin{tabular}{|c|c|c|c|}
\hline \multicolumn{4}{|l|}{ Análisis univariado } \\
\hline Variable & $\mathbf{R R}$ & IC $95 \%$ & $p$ \\
\hline Desnutrición & 0,85 & $0,79-0,92$ & $<0,01$ \\
\hline $\begin{array}{l}\text { Antecedente de internación } \\
\text { previa de causa respiratoria }\end{array}$ & 0,81 & $0,78-0,84$ & $<0,01$ \\
\hline Inmunosupresión & 0,81 & $0,71-0,92$ & $<0,01$ \\
\hline Bronquiolitis como & & & \\
\hline presentación clínica & 1,11 & $1,08-1,14$ & $<0,01$ \\
\hline Edad $<3$ meses & 1,16 & $1,13-1,19$ & $<0,01$ \\
\hline $\begin{array}{l}\text { Enfermedad aguda } \\
\text { en contactos }\end{array}$ & 1,04 & $1,02-1,07$ & $<0,01$ \\
\hline Hipoxemia & 1,14 & $1,07-1,22$ & $<0,01$ \\
\hline Uso de broncodilatadores & 1,25 & $1,09-1,45$ & $<0,01$ \\
\hline Prematurez & 0,90 & $0,86-0,94$ & $<0,01$ \\
\hline $\begin{array}{l}\text { Antecedentes } \\
\text { respiratorios perinatales }\end{array}$ & 0,88 & $0,84-0,93$ & $<0,01$ \\
\hline $\begin{array}{l}\text { Uso de antibióticos durante } \\
\text { la internación }\end{array}$ & 0,89 & $0,87-0,92$ & $<0,01$ \\
\hline
\end{tabular}

Análisis multivariado

\begin{tabular}{lccc} 
Variable & OR & IC 95\% & $p$ \\
\hline Bronquiolitis como & & & \\
presentación clínica & 1,54 & $1,32-1,79$ & $<0,01$ \\
Edad $<3$ meses & 2,80 & $2,14-3,67$ & $<0,01$ \\
Hipoxemia & 1,84 & $1,42-2,37$ & $<0,01$ \\
\hline
\end{tabular}

Buenos Aires en 1999, fue el más frecuente dentro de este subtipo en la población estudiada. ${ }^{19,20}$ Con respecto a los genotipos encontrados para el subtipo A, co-circularon el genotipo GA2 y el GA5, principalmente en el período 2000-2008, mientras que, en el año 2009, surgió un nuevo genotipo llamado NA1, muy relacionado con el GA2 pero que fue reemplazándolo en los años siguientes. Llamativamente, en el año 2012, comenzó a circular en nuestra región una cepa de VRS subtipo A con una duplicación de 24 aminoácidos en la glicoproteína $\mathrm{G}$, denominado genotipo ON1.

\section{DISCUSIÓN}

Las IRAB son una importante causa de morbimortalidad, consulta médica y hospitalización en los primeros años de vida.

El VRS fue el agente viral más frecuentemente hallado en nuestra población como causa de IRAB; este hallazgo coincide con datos de la literatura internacional. ${ }^{21-25}$ En los 14 años de nuestro estudio, predominó el VRS sobre el resto de los virus circulantes, incluido el año 2009, durante el cual transcurrió la pandemia de influenza A H1N1, porque si bien hubo un desplazamiento en su aparición durante el período de mayor circulación pandémica, el número total de casos de IRAB por VRS superó en número a los casos producidos por este virus.

El análisis de las características genotípicas de las cepas de VRS muestra que es posible que la plasticidad que tiene este virus para acomodar cambios tan drásticos en sus proteínas de superficie le den ventajas evolutivas que permitan subvertir la respuesta inmune previamente generada y, de esta forma, circular en la población pediátrica y continuar siendo el agente viral más frecuente en niños con IRAB menores de un año.

En regiones con clima templado, el VRS tiene una marcada estacionalidad, caracterizada por la aparición de un brote anual durante los meses de menor temperatura. Pudimos objetivar claramente la estacionalidad del VRS con predominio durante los meses de mayo a julio, con diferencias anuales en relación con la magnitud y el tiempo de inicio del brote.

Se han encontrado diferencias entre la magnitud de los brotes anuales de VRS que llevaron a la descripción de "ciclos bienales", en los que alternan brotes mayores de inicio temprano con otros menores y más tardíos. ${ }^{1}$ Este comportamiento cíclico bianual del VRS fue descrito inicialmente en Europa y, en nuestra serie 
de 14 años, pudimos comprobar esta alternancia en los últimos 5 años, similar a lo mencionado por distintos estudios. ${ }^{26,27}$ El valor de estos datos aun es limitado, pero de comprobarse cierta regularidad en los ciclos, resultaría de fundamental importancia para la programación de acciones sanitarias. ${ }^{1}$

El mayor brote de VRS se presentó en el año 2003, aunque también se observaron brotes importantes en los años 2010 y 2012 de inicio temprano, alternados con brotes de menor magnitud e inicio más tardío en el resto de los años.

Según los datos obtenidos en relación con la incidencia hospitalaria anual de bronquiolitis en nuestro centro, el $41 \%$ de ellas fueron causadas por el VRS, lo que coincide con numerosos estudios realizados en niños menores de 5 años hospitalizados por IRAB. ${ }^{1}$ La bronquiolitis como forma de presentación más usual se manifiesta con un predominio en los lactantes entre las 6 semanas y los 9 meses de vida con un pico de incidencia entre los 2 y los 7 meses, hallazgos también descritos por diversos trabajos a nivel mundial. ${ }^{28-30}$ En nuestra serie, el 60,7\% de los casos presentó bronquiolitis al momento del ingreso, mientras que el 39,3\% restante lo hizo como neumonía. Debemos recordar que los virus representan la causa más frecuente de neumonía adquirida en la comunidad, en especial en menores de 2 años. ${ }^{1,2}$

La población considerada de alto riesgo son los niños con enfermedad pulmonar crónica, cardiopatía congénita y prematurez; su riesgo de hospitalización es superior al de la población general. Coincidentemente con nuestros resultados, se observó que más del 41,5\% de los niños que se internaron por IRAB por VRS tenían alguna patología de base. Las más frecuentes eran enfermedad respiratoria crónica, cardiopatía congénita, prematurez, enfermedad neurológica crónica, desnutrición e inmunosupresión. ${ }^{11}$ Estos datos podrían estar magnificados dado que nuestro Hospital es un centro de referencia nacional, en el cual se atienden habitualmente niños con dichas patologías, lo que podría constituir una debilidad del estudio.

Un cuarto de nuestra población presentó alguna complicación. Las más frecuentes fueron la otitis media aguda $(24,8 \%)$ y la atelectasia $(14,4 \%)$. Trabajos internacionales estiman que el VRS sería el principal virus asociado a otitis media aguda en niños ${ }^{31}$ y que la infección mixta virus-bacteria en el oído medio puede empeorar el curso de la OMA. ${ }^{32}$
En cuanto a la letalidad asociada a VRS en menores de 1 año, se estima en $0,7 \%(0,3-4,8)$ para niños sanos en países industrializados y en $2,1 \%(1,6-2,2)$ para niños nacidos en países de bajos ingresos, lo que coincide con los resultados obtenidos en nuestro estudio (letalidad: $1,9 \%$ ). ${ }^{33}$

Por último, la transmisión intrafamiliar de VRS descrita resulta significativa, teniendo en cuenta que es del $46 \%$ en convivientes, con un índice de casos secundarios del $27 \% .{ }^{1}$ Esto se relaciona con el hallazgo en nuestro estudio de que cerca de la mitad de los casos refería haber tenido contacto intrafamiliar o cercano con personas agudamente enfermas.

En el Calendario Nacional de Inmunizaciones, se han introducido vacunas que permiten disminuir la carga de enfermedad por IRAB, tales como las provocadas por Bordetella pertussis (componente de las vacunas triple bacteriana, quíntuple o séxtuple), virus influenza y Streptococcus pneumoniae. Estas vacunas han tenido considerable impacto si bien aún se deben ajustar las coberturas de vacunación de las diferentes jurisdicciones y departamentos. Desafortunadamente, continúa pendiente el desarrollo de una vacuna contra el VRS. En la actualidad, hay numerosas líneas de investigación que permitirían incluso pensar en su administración en el embarazo y así prevenir las infecciones en las etapas más tempranas de la vida. ${ }^{18}$

De acuerdo con lo descrito anteriormente, podemos afirmar que el VRS es uno de los agentes virales de mayor relevancia clínica en pediatría. En la última década, el avance más significativo sobre la prevención de esta enfermedad ha sido el desarrollo del palivizumab, un anticuerpo monoclonal humanizado que se fija a la proteína F del VRS y evita la adherencia del virus a la membrana basal del epitelio respiratorio. Su indicación está limitada a prematuros, niños menores de 2 años que padecen displasia broncopulmonar sintomática y/o cardiopatías congénitas, ya que constituyen la población con riesgo elevado de padecer formas graves y muerte por infección respiratoria por VRS con respecto a los lactantes sin esos antecedentes. La importancia de su uso está claramente demostrada en este trabajo cuando se observa el riesgo de los pacientes con estas patologías de base., ${ }^{1,34}$

Sin duda, el impacto que produce el VRS para el sistema de salud y para la población en general es de gran importancia. Conocer estos datos permite ajustar patrones de diagnóstico 
y seguimiento de los pacientes al igual que de las políticas sanitarias por implementar. Es fundamental facilitar las estrategias de derivación de los pacientes hacia las áreas de alta complejidad y su atención en estos casos a los fines de disminuir la morbimortalidad de nuestros pacientes más vulnerables mientras se espera la aparición de una vacuna efectiva.

\section{CONCLUSIONES}

En nuestra serie, el VRS fue el agente predominante en todos los años estudiados, que presentó un patrón epidémico estacional (mayojulio). Se asoció más a niños pequeños menores de tres meses con bronquiolitis e hipoxemia al momento del ingreso.

\section{Agradecimientos}

Al Servicio de Virología y al plantel del Hospital de Niños Ricardo Gutiérrez por su generosa colaboración.

\section{REFERENCIAS}

1. Sociedad Argentina de Pediatría. Comité de Infectología Pediátrica. Libro Azul de Infectología Pediátrica. 4ta ed. Buenos Aires: SAP; 2012. Págs.413-7.

2. American Academy of Pediatrics. Respiratory Syncytial Virus. En: Pickering LK, ed. Red Book: 2012 Report of the Committee on Infectious Diseases. 29th ed. Elk Grove Village, IL: American Academy of Pediatrics; 2012. Págs.609-18.

3. UN Inter-agency Group for Child Mortality Estimation. Level \& Trends in Child Mortality. Report 2013. New York, 2013. Disponible en: http://www.childmortality. org/files_v16/download/UNICEF\%202013\%20IGME\%20 child $\% 20$ mortality\%20Report_Final.pdf. [Consulta: 5 de junio de 2014].

4. Secretaría de Políticas, Regulación e Institutos. Dirección de Estadísticas e Información deSalud. Estadísticas vitales. Información básica año 2012. Buenos Aires: Ministerio de Salud de la Nación Argentina; 2013. Serie 5 - Número 56.

5. Comité de infecciones respiratorias de la Sociedad Latinoamericana de Infectología Pediátrica. Consenso de la Sociedad Latinoamericana de Infectología Pediátrica sobre neumonía adquirida en la comunidad. Rev Enferm Infecc Pediatr 2010;24(94):1-23.

6. Portillo C, Cruz J. Implementación del método rápido de diagnóstico de virus por inmunofluorescencia en niños hospitalizados por infecciones respiratorias agudas. Arch Argent Pediatr 2000;98(2):99-102.

7. Nair H, Nokes DJ, Gessner BD, Dherani M, et al. Global burden of acute lower respiratory infections due to respiratory syncytial virus in young children: a systematic review and meta-analysis. Lancet 2010;375(9725):1545-55.

8. Griffin MR, Walker FJ, Iwane MK, Weinberg GA, et al. Epidemiology of respiratory infections in young children: insights from the new vaccine surveillance network. Pediatr Infect Dis J 2004;23(11 Suppl):S188-92.

9. Sadeghi C, Aebi C, Gorgievski-Hrisoho M, Mühlemann $\mathrm{K}$, et al. Twelve years' detection of respiratory viruses by immunofluorescence in hospitalised children: impact of the introduction of a new respiratory picornavirus assay. BMC Infect Dis 2011. Págs.11:41.
10. Jokela P, Piiparinen H, Luiro K, Lappalainen M. Detection of human metapneumovirus and respiratory syncytial virus by duplex real-time RT-PCR assay in comparison with direct fluorescent assay. Clin Microbiol Infect 2010;16(10):1568-73.

11. Hall CB, McCarthy CA. Respiratory Syncytial Virus. En: Mandell GL, BennettJE, Dolin R, eds. Principles and Practices of Infectious Diseases 4th ed. New York, USA: Churchill Livingstone; 1995. Págs.1501-18.

12. Ferrero FC, González Pena H, Ossorio MF, Grenoville M. Consenso sobre infecciones respiratorias agudas bajas en menores de 2 años. Arch Argent Pediatr 1996;94(4):274-88.

13. Hall CB, Weinberg GA, Iwane MK, Blumkin AK, et al. The burden of respiratory syncytial virus infection in young children. N Engl J Med 2009;360(6):588-98.

14. Hall CB. Respiratory syncytial virus and parainfluenza virus. N Engl J Med 2001;344(25):1917-28.

15. Prendergast $C$, Papenburg J. Rapid antigen-based testing for respiratory syncytial virus: moving diagnostics from bench to bedside? Future Microbiol 2013;8(4):435-44.

16. Korppi M, Kotaniemi-Syrjänen A, Waris M, Vainionpää R, Reijonen TM. Rhinovirus-associated wheezing in infancy: comparison with respiratory syncytial virus bronchiolitis. Pediatr Infect Dis J 2004;23(11):995-9.

17. Jartti $T$, Lehtinen $P$, Vuorinen $T$, Osterback $R$, et al. Respiratory picornaviruses and respiratory syncytial virus as causative agents of acute expiratory wheezing in children. Emerg Infect Dis 2004;10(6):1095-101.

18. Anderson LJ. Respiratory syncytial virus vaccine development. Semin Immunol 2013;25(2):160-71.

19. Trento A, Galiano M, Videla C, Carballal G, et al. Major changes in the $G$ protein of human respiratory syncytial virus isolates introduced by a duplication of 60 nucleotides. J Gen Virol 2003;84(Pt 11):3115-20.

20. Trento A, Viegas M, Galiano M, Videla C, et al. Natural history of human respiratory syncytial virus inferred from phylogenetic analysis of the attachment (G) glycoprotein with a 60-nucleotide duplication. J Virol 2006;80(2):975-84.

21. Glezen WP, Greenberg SB, Atmar RL, Piedra PA, et al. Impact of respiratory virus infections on persons with chronic underlying conditions. JAMA 2000;283(4):499-505.

22. Iwane MK, Edwards KM, Szilagyi PG, Walker FJ, et al. Population-based surveillance for hospitalizations associated with respiratory syncytial virus, influenza virus, and parainfluenza viruses among young children. Pediatrics 2004;113(6):1758-64.

23. GentileA,BakirJ,Moar A,BurnaV, etal.Perfilepidemiológico de las infecciones respiratorias agudas bajas en un hospital pediátrico. Arch Argent Pediatr 1996;94(1):2-9.

24. Maffey AF, Venialgo CM, Barrero PR, Fuse VA, et al. Nuevos virus respiratorios en niños de 2 meses a 3 años con sibilancias recurrentes. Arch Argent Pediatr 2008;106(4):3029.

25. Speranza AM, Clary AL, Pereira T, Sapoznicoff L, et al. Estudio multicéntrico de infecciones respiratorias agudas bajas en niños hospitalizados menores de dos años. Arch Argent Pediatr 2003;101(5):365-73.

26. Viegas M, Barrero PR, Maffey AF, Mistchenko AS. Respiratory viruses seasonality in children under five years of age in Buenos Aires, Argentina: a five-year analysis. J Infect 2004;49(3):222-8.

27. Walton NA, Poynton MR, Gesteland PH, Maloney C, et al. Predicting the start week of respiratory syncytial virus outbreaks using real time weather variables. BMC Med Inform Decis Mak 2010;10:68.

28. Shay DK, Holman RC, Newman RD, Liu LL, et al. Bronchiolitis-associated hospitalizations among US children, 1980-1996. JAMA 1999;282(15):1440-6.

29. Lowther SA, Shay DK, Holman RC, Clarke MJ, et al. 
Bronchiolitis-associated hospitalizations among American Indian and Alaska Native children. Pediatr Infect Dis J 2000;19(1):11-7.

30. Viegas M. Epidemiología molecular del virus sincicial respiratorio en pacientes pediátricos en un período de seis años. Acta Bioquím Clín Latinoam 2011;45(1):3-45.

31. Heikkinen T, Waris M, Ruuskanen O, Putto-Laurila A, et al. Incidence of acute otitis media associated with group $A$ and B respiratory syncytial virus infections. Acta Paediatr 1995;84(4):419-23.
32. Corbeel L. What is new in otitis media? Eur J Pediatr 2007;166(6):511-9.

33. Giubergia V, Martinchuk G, Moreno N, Colombres G, et al. Gravedad de la infección por virus sincicial respiratorio en pacientes con factores de riesgo y sin ellos. Arch Argent Pediatr 2004;102(5):330-4.

34. ComitédeEstudios Fetoneonatales (CEFEN). Actualización de las recomendaciones sobre el uso de palivizumab. Arch Argent Pediatr 2007;105(1):67-70.

\section{Archivos hace 75 años}

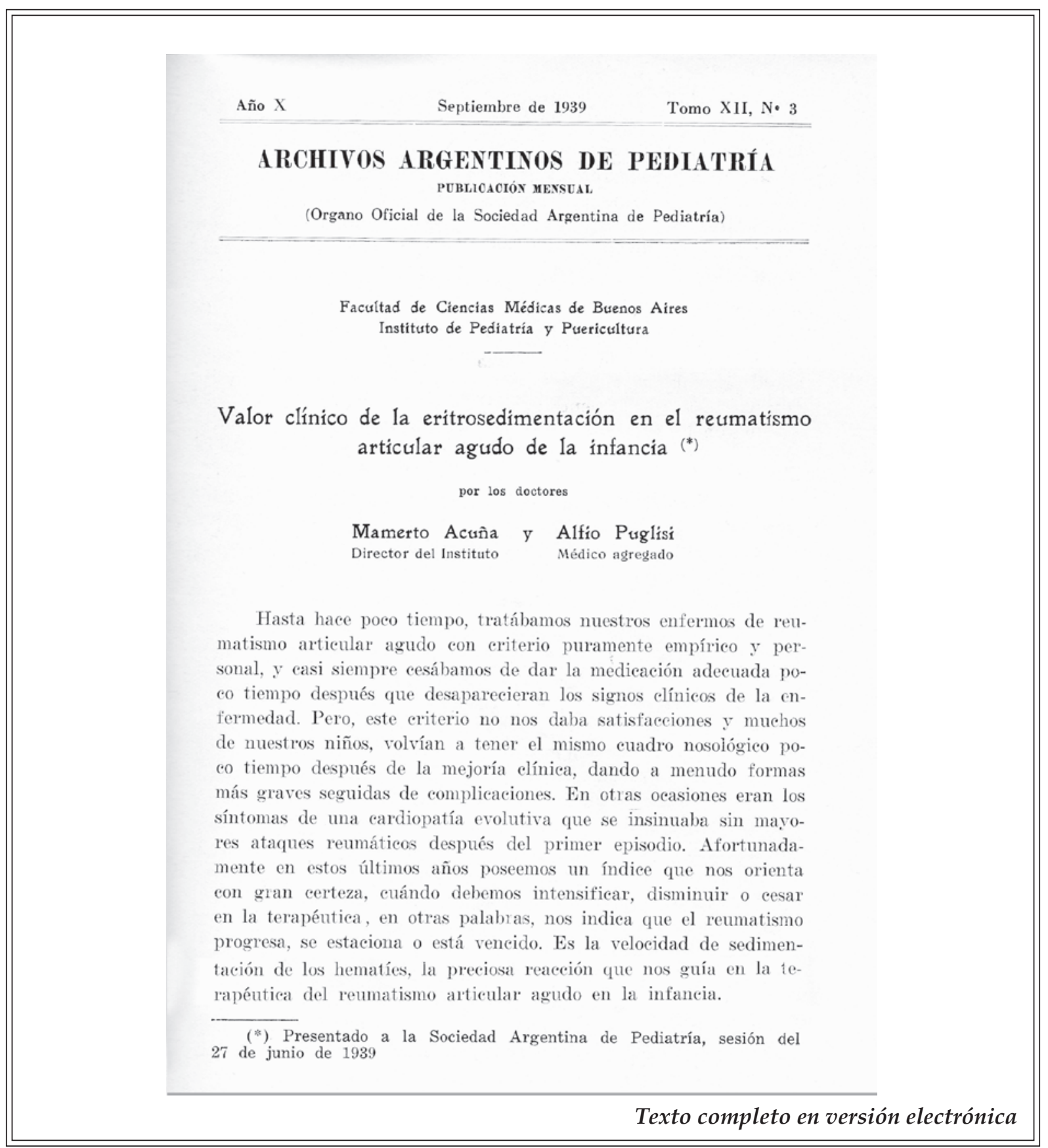

